1 Universidade Federal da Bahia (UFBA), Instituto de Saúde Coletiva (ISC), Programa de PósGraduação em Saúde

Coletiva - Salvador (BA), Brasil.

jamillyss@hotmail.com

2 Universidade Federal da Bahia (UFBA), Instituto de Saúde Coletiva (ISC), Programa de PósGraduação em Saúde

Coletiva - Salvador (BA),

Brasil.

carment@ufba.br

\section{Crise, refundação do Cebes e reafirmação do projeto da Reforma Sanitária Brasileira}

\author{
Crisis, refoundation Cebes and restatement of the project of Brazilian \\ Health Reform
}

Jamilli Silva Santos', Carmen Fontes Teixeira ${ }^{\mathbf{2}}$

RESUMO O objetivo deste trabalho é analisar o processo de 'refundação' do Centro Brasileiro de Estudos de Saúde (Cebes) e o seu posicionamento político no período 2005-2014. As fontes são 40 editoriais da revista 'Saúde em Debate' e 11 position papers da entidade. Os resultados descrevem a crise no Cebes em 2005, o processo de refundação e a atuação da entidade em defesa da Reforma Sanitária Brasileira, do direito universal à saúde, da consolidação do Sistema Único de Saúde e da radicalização da democracia. Conclui-se que o Cebes é um sujeito político coletivo cujo posicionamento se contrapõe aos projetos mercantilista e racionalizador que disputaram a direcionalidade da política de saúde implementada pelo governo federal nesse período.

PALAVRAS-CHAVE Política de saúde. Reforma dos serviços de saúde. Sistema Único de Saúde.

ABSTRACT This study that aims to analyze the process of re-foundation of the Brazilian Center for Health Studies (Cebes) and its political position in the period 2005-2014. The sources are 40 editorials from the periodic 'Saúde em Debate' and 11 position papers of the entity. The results describe the crisis in Cebes and the process of refounding the entity's activities in defense of the Brazilian Health Reform, the universal right to health, the consolidation of the Unified Health System, and the radicalization of democracy. We conclude that Cebes it is a collective political subject whose position is opposed to the mercantilist and rationalizing projects that competed in the directionality of the health policy implemented by the federal government in that period.

KEYWORDS Health policy. Health care reform. Unified Health System. 


\section{Introdução}

A Reforma Sanitária Brasileira (RSB) tem sido estudada por vários autores (ESCOREL, 2008; FLEURY, 1989; 1994; PAIM, 2008) que descrevem sua emergência enquanto 'movimento sanitário' nos anos 1970, cenário de elaboração da proposta de mudança na política e na organização do sistema de saúde. Analisam ainda sua transformação em projeto político nos anos 1980, quando suas propostas foram incorporadas à Constituição Federal de 1988, e os diversos momentos do processo de implantação do Sistema Único de Saúde (SUS) nos últimos 28 anos (1988-2016).

O Centro Brasileiro de Estudos de Saúde (Cebes), criado em 1976, atuou como protagonista nesse processo (ESCOREL, 1999), constituindo-se no espaço em que foi formulada a proposta original de 'democratização da saúde' (CEBES, 1979) e em um dos principais articuladores do projeto institucionalizado a partir da aprovação do capítulo saúde da Constituição Federal de 1988, da legislação básica do SUS e da implementação das estratégias de construção desse sistema (FLEURY, 1994; PAIM, 2008; 2013A).

A atuação dessa entidade nos seus dez primeiros anos de existência foi objeto de estudo pioneiro de Sophia (2015), que retraçou o contexto político e sanitário no qual foi criado o Centro, enfocando os determinantes sociais e políticos de sua criação e seu posicionamento político no período 1976-1986, basicamente a partir da análise do conteúdo da revista 'Saúde em Debate' (RSD), órgão veiculador do pensamento cebiano, em torno do qual se articulou o trabalho político e cultural da entidade.

Uma revisão da literatura científica da área de política de saúde no Brasil, realizada na base bibliográfica Scientific Electronic Library Online (SciELO) (SANTOS; TEIXEIRA, 2016), não revelou artigos que tratassem especificamente da trajetória e atuação do Cebes no período posterior à realização da VIII Conferência Nacional de Saúde, porém cabe registrar a publicação do livro 'Saúde e democracia: a luta do Cebes' (FLEURY, 1997), por ocasião da comemoração dos 20 anos de existência do Centro, que sistematizou o conjunto de temas que constituem seus principais objetos de reflexão e atuação política.

Nos últimos 20 anos, o Cebes atravessou diversas crises (CEBES, 2005C), tendo passado mais recentemente por um processo denominado 'refundação' (CEBES, 2005E). Esse processo constitui o tema do presente estudo, cujo objetivo é analisar a atuação do Cebes no período 2003-2014, em que ocorre a crise que conduziu à refundação da entidade em 2006, tratando, especificamente de identificar seu posicionamento com relação à RSB.

\section{Aspectos teórico- metodológicos}

O estudo do 'processo político em saúde' compreende a análise da atuação das organizações governamentais formalmente incumbidas da formulação e implementação de políticas e da gestão do sistema de saúde, bem como a análise da atuação de outros sujeitos ou organizações, que, como assinala Testa (2007), têm capacidade de introduzir temas de discussão na agenda do Estado e, portanto, interferem na tomada de decisões acerca da seleção e enfrentamento dos problemas nesta área.

O Estado constitui uma arena de conflitos, 'espaço social', físico ou virtual, em que se encontram múltiplos atores, isto é, representantes de grupos, instituições, partidos políticos, envolvidos em processos de mobilização, participação e tomada de decisões que comportam negociações e acordos com relação à política e organização do sistema de saúde. Os diversos 'sujeitos' se inter-relacionam, influenciando as ações uns dos outros, sendo que a atuação de cada um deles pode apresentar período de maior ou menor intensidade em determinadas conjunturas, de acordo com sua capacidade de 
organização e vocalização de suas demandas e propostas (TESTA, 2007).

O Cebes, entidade criada em 1976 com o objetivo de veicular um pensamento crítico e articular ações políticas em prol da democratização da saúde e da sociedade brasileira (FLEURY, 1997), pode ser entendido com um sujeito político coletivo (TESTA, 1995), que representa indivíduos e grupos sociais que se identificaram com um projeto político de mudança da política de saúde vigente no período autoritário (PAIM, 2008), atuando em um cenário, no caso, o 'setor saúde', entendido como um espaço social em que transcorrem os processos (discussão, conflitos, decisões, ação) relativos à formulação, implementação e avaliação da política de saúde.

Desse modo, o Cebes tem participado, ao longo dos últimos 40 anos, da disputa em torno da concepção política mais ampla em relação à saúde como direito universal ou como mercadoria, bem como das disputas em torno das propostas de mudança e/ou conservação referentes ao financiamento, organização e gestão do sistema público de saúde e de sua relação com o setor privado, tanto as empresas e o financiamento de produção de serviços quanto a indústria de produção de insumos e tecnologias utilizadas no sistema de saúde. Tal disputa se encontra na base do confronto entre o projeto da RSB (PAIM, 2008) e os demais projetos que se apresentam no cenário político brasileiro (PAIM, 2013A), quais sejam: o mercantilista, que reflete os interesses do capital na área de saúde, e o projeto racionalizador, resultante das negociações e articulações que se passam ao interior das instituições estatais na área de saúde, onde se disputa o poder cotidiano e o poder societal (TESTA, 1995).

O presente trabalho insere-se em uma investigação mais ampla acerca do processo de Reforma Sanitária no período 2007-2016 (PAIM, S.D.) e constitui um estudo de caso, de caráter exploratório e descritivo, baseado na análise de documentos elaborados e divulgados pela direção nacional do Cebes no período 2003-2014. Foram analisados 11 documentos e 40 editoriais da RSD disponibilizados no site da entidade (http://cebes. org.br/). Construiu-se uma 'linha do tempo' que incluiu a periodização dos governos que se sucederam no período estudado, os principais fatos e acontecimentos que marcaram a trajetória da política de saúde, as diretorias do Cebes eleitas ao longo do período e os documentos citados anteriormente. Com base nessa linha do tempo, foram estabelecidos os diversos 'momentos' da história recente do Cebes, distinguindo-se: a) 'crise e refundação (2005-2006)', momento em que se evidenciou uma crise interna que gerou um debate sobre a viabilidade de sua permanência, o qual confluiu para a chamada 'refundação do Cebes'; b) reativação do Cebes (20072014), período em que a entidade atuou continuamente no cenário político em saúde, posicionando-se, por meio de documentos, editoriais e números especiais da RSD.

\section{Crise e refundação do Cebes (2005-2006)}

A trajetória do Cebes foi marcada por momentos de crise, relacionados com a atualização do debate interno sobre o papel a ser desempenhado pela entidade, bem como com a garantia de sua sustentação financeira, inclusive pelo fato desta contar quase que exclusivamente com recursos provenientes das anuidades pagas por seus associados, complementados por convênios/ auxílios destinados à edição de suas revistas (CEBES, 2005B).

A maior dessas crises aconteceu no final do período em que Sarah Escorel esteve à frente da entidade (2000-2005), quando ocorreu uma profunda reflexão sobre $\mathrm{o}$ futuro do Cebes, seu papel na conjuntura e como mantê-lo funcionando, cogitando-se até mesmo a sua dissolução ou fusão com a Associação Brasileira de Saúde Coletiva (Abrasco) (CEBES, 2005B). Tal crise eclodiu 
inicialmente por razões financeiras, mas se desdobrou na reflexão acerca do posicionamento do Centro com relação à política de saúde adotada no primeiro governo do presidente Luís Inácio Lula da Silva (CEBES, 2005C).

A conjuntura política inaugurada com a mudança de governo em 2003 e as ações desenvolvidas na área de saúde pelo Governo Lula (leia-se, Ministério da Saúde - MS), sob a gestão de Humberto Costa, foram analisadas pelo Cebes evidenciando o descontentamento com a gestão financeira do SUS nesse período, chamando-se a atenção para que

[...] voltamos a enfrentar situações frequentes de quando éramos governados pelos representantes da elite: a proposta orçamentária de 2004 para a saúde desrespeita a EC 29. (CEBES, 2003, P. 91).

Apesar de o Cebes reconhecer a pertinência de algumas ações desenvolvidas no primeiro ano do governo petista a exemplo da qualificação da gestão do SUS, "implantação/reestruturação de unidades de saúde" e "elaboração do Plano Nacional de Saúde" (CEBES, 2004, P. 89), tais ações foram consideradas insuficientes para a efetivação do direito à saúde (CEBES, 2004).

Ao longo do ano de 2005, o Cebes concentrou o foco de seus editoriais na reflexão sobre a crise interna e as possibilidades de superação. Nesse contexto, os associados foram chamados pela Diretoria Nacional a debater a situação e o futuro do Centro, tendo, nessa ocasião, sido apresentadas as seguintes opções: 1) manutenção do Cebes, com aprimoramento de suas atividades editoriais; 2) dissolução da entidade; e 3) fusão total ou parcial à Abrasco, processo cujos termos e significado deveriam ser discutidos, não só internamente ao Cebes, mas também com os próprios associados e com a diretoria da Abrasco (CEBES, 2005B).

Diante das referidas alternativas e considerando o lugar de destaque do Cebes na história da RSB e a importância da manutenção dos periódicos por ele editados (RSD e Divulgação em Saúde para Debate), enquanto publicações "[...] daqueles que atuam e militam no Sistema Único de Saúde" (CEBES, 2005c, p. 107), os associados decidiram, em Assembleia Geral, que seria importante a manutenção e aprimoramento da entidade.

Uma vez tomada essa decisão, algumas iniciativas foram desencadeadas tendo em vista a reestruturação da entidade. Entre elas, a reorganização financeira para garantir sua sustentação e, inclusive, a permanência da linha editorial (RSD e Divulgação em Saúde para Debate) que constitui a espinha dorsal da entidade. A importância da manutenção desses periódicos foi enfatizada pelo fato de que eles "[...] abrem espaço para autores oriundos dos serviços de saúde, assim como para acadêmicos fora do eixo Sul-Sudeste" (CEBES, 2005C, P. 107), além de que os documentos e artigos publicados em seus diversos números constituem um "[...] registro histórico [...] sobre a Política Nacional de Saúde”, permitindo a difusão de experiências locais, estaduais e nacionais da área da Saúde, constituindo-se, portanto, em importantes veículos de divulgação dos debates da RSB (CEBES, 2005C, P. 107).

$O$ processo de reorganização financeira da entidade, por sua vez, foi realizado a partir da progressiva regularização do pagamento da anuidade pelos associados, estimulada pelos diversos apelos do Centro em seus editoriais, e de inúmeros apoios recebidos por meio da compra de parte do estoque de revistas e livros, do recebimento de doação de recursos e da realização de convênios para publicação das revistas. Tal apoio contou com a participação de diversas entidades e instituições, como: Abrasco, Centro de Pesquisas Aggeu Magalhães, Conselho Nacional de Secretarias Municipais de Saúde, Fundação Oswaldo Cruz (Fiocruz) e Rede Unida (CEBES, 2005B).

Nessa reestruturação, o retorno às atividades propriamente políticas se deu com a participação do Centro no VIII Simpósio sobre 
Política de Saúde da Câmara dos Deputados, ocorrido em junho de 2005 (CEBES, 2005B), que resultou na 'Carta de Brasília', divulgada na RSD. Nessa Carta, são defendidos, entre outros pontos: redistribuição de renda de cunho social; reafirmação da seguridade social; defesa dos princípios e diretrizes do SUS; revisão dos subsídios e isenções fiscais para operadores e prestadores privados de planos e seguros de saúde; e manifestação contrária à terceirização da gerência e gestão de serviços e de pessoal da saúde (CEBES, 2005A).

Ainda nesse ano, uma nova diretoria foi eleita, sob presidência de Sonia Fleury, para a gestão 2006-2009, com o compromisso de dirigir a refundação do Centro e revitalizar seus instrumentos de comunicação (CEBES, 2005C). Para isso, a nova diretoria desencadeou um processo de reagrupamento dos 'cebianos', intelectuais e representantes de movimentos sociais organizados, por meio da realização de uma série de seminários nos quais foram abordados os seguintes temas: participação social e democracia, seguridade social e determinação social da saúde, os quais geraram, posteriormente, a publicação de uma coleção intitulada 'Pensar em saúde' (FLEURY; LOBATO, 2009). O processo de refundação foi, portanto, um reencontro do Centro com as pautas que mobilizaram sua criação nos anos 1970 e 1980, ao mesmo tempo que sinalizou a necessidade de atualização dessa agenda em virtude de demandas e temas que não estavam presentes naquela ocasião.

O trabalho da referida gestão iniciou-se com a publicação de dois documentos, a 'Plataforma de refundação' (CEBES, 2005E) da entidade e 'A identidade política do Cebes' (CEBES, 2005D), os quais visavam nortear o processo de revitalização e consolidação do Cebes (CEBES, 2005C). Em ambos os documentos, a entidade assumiu e reafirmou as principais características que a definem, as bandeiras que defende e as estratégias que desenvolve, sendo que o primeiro enfatiza a atuação política setorial e o segundo aponta para uma ação política e social mais ampla.
A Plataforma de refundação enfatiza que "O Cebes é um espaço plural e não partidário, comprometido com a construção da Democracia e Saúde" (CEBES, 2005E, P. 227), explicitando que

[...] a democracia vai além da institucionalidade e da representação, passando pela construção de uma esfera pública plural e inclusiva, na qual os cidadãos se reconheçam como iguais e sujeitos de direitos. (CEBES, 2005E, P. 227).

Nesse sentido, a entidade chama a atenção para que

Mais do que atuar na trincheira do aparato estatal, o Cebes tem como missão a luta pela hegemonia, participando na construção e ampliação da consciência sanitária e na constituição de sujeitos políticos emancipados. (CEBES, 2005E, P. 227).

Ao refletir sobre o processo de RSB, a entidade destaca os avanços conquistados, sobretudo quanto à institucionalização do direito à saúde, porém reconhece a “[...] redução do poder de transformação do movimento sanitário" (CEBES, 2005E, P. 227-228). Nesse sentido, reafirma sua atuação conforme as duas naturezas que a compõem: movimento social, "capaz de empolgar pelo vigor de sua proposta", e organização social, "capaz de incidir na realidade com a clareza de suas propostas e sua capacidade de articulação política" (CEBES, 2005E, P. 228). Quanto à efetivação do direito à saúde no cotidiano da população, a entidade destaca os caminhos a serem percorridos, por meio de uma

ação política contundente e não conivente com o clientelismo e a corrupção [...] a fim de demonstrar que um sistema público universal, de qualidade e humanizado é viável, hoje. (CEBES, 2005E, P. 228).

Diante dessas reflexões, a entidade aponta como estratégia de atuação a "[...] 
construção e ampliação da consciência sanitária e a constituição de sujeitos políticos emancipados" (CEBES, 2005E, P. 227), bem como a articulação com os movimentos nacionais e internacionais com fins semelhantes e com demais atores políticos da sociedade civil organizada (CEBES, 2005E, P. 228); pois acredita que apenas com uma organização forte da sociedade civil se poderá alcançar a radicalização da democracia (CEBES, 2005E).

Essa ideia-proposta reaparece no documento que apresenta a reflexão sobre a identidade política do Cebes no qual se afirma que "[...] a identidade coletiva que nos agrega é a de uma instituição comprometida com o socialismo, e [...] com a radicalização da democracia" (CEBES, 2005D, P. 397), o que torna necessária "uma verdadeira transformação nas relações de poder, o que não ocorreu com a mudança de regime político" (CEBES, 2005D, P. 397).

Ao entender a peculiaridade de sua composição e direcionamento político, a entidade caracteriza-se, portanto, como parte das organizações e movimentos da sociedade civil que buscam a transformação social, por meio do uso dos

[...] conhecimentos e saberes para demarcar este lugar de um pensamento de esquerda, que tensione o espectro político mais tradicional e cobre mudanças institucionais e societárias. (CEBES, 2005D, P. 397).

Sobre a missão da entidade, ultrapassando o limite setorial, o documento defende medidas de amplo espectro condizentes com os ideais da RSB, ao propor

[...] cobrar a universalidade, reivindicando um projeto coletivo de Reforma Sanitária que transcenda interesses [...] particularistas, exigindo a transformação da democracia atual em uma democracia substantiva. (CEBES, 2005D, P. 397).

Destaca ainda o desafio e importância da manutenção da autonomia diante do
Estado, uma vez que a entidade deve manter uma postura crítica necessária para fazer a reforma avançar, e, sobretudo, cobrar posições governamentais em relação a pontos polêmicos (CEBES, 2005E). Nessa perspectiva, o Centro problematiza o desafio atual

[...] de manter-se como uma organização autônoma, desvinculada do Estado e ao mesmo tempo em que buscamos inserir nossas bandeiras na arena política, conquistando aliados dentro e fora do Estado. (CEBES, 2005D, P. 397).

Tal reflexão torna-se relevante também diante da inserção de alguns dos militantes do Centro, chamados carinhosamente de "companheiros" (CEBES, 2005D, P. 398) nos núcleos decisórios do Estado, o que, para a direção nacional, reforça a necessidade de manutenção de tal princípio. Nesse particular, o documento destaca pontos polêmicos que provavelmente representariam possíveis embates dos militantes dos diversos núcleos com o governo, tanto no âmbito federal quanto estadual e municipal, como, por exemplo: ameaça à universalização da saúde por medidas econômicas; "[...] redução de benefícios para a população mais pobre; [...] ausência de uma proposta coerente de reforma do Estado" (CEBES, 2005D, P. 398).

Definidas a essência e a linha de atuação política, a entidade dedicou-se também, nesse documento, a sistematizar as estratégias de atuação para o alcance de objetivos traçados, quais sejam: a articulação com organizações, movimentos e partidos políticos em torno das questões sanitárias, o que depende da construção de um SUS de qualidade, que estimule o apoio da população, e ainda, da manutenção permanente da análise de conjuntura política (CEBES, 2005D). Além disso, o Cebes defende também a realização de ações pontuais, como a participação em espaços de discussão política em saúde que aconteceriam no período (Congressos da Abrasco - 2006, da Associação LatinoAmericana de Medicina Social e Saúde 
Coletiva - 2007 e XIII Conferência Nacional de Saúde - 2007), bem como o fortalecimento de canais de veiculação de informação por meio da retomada da periodicidade da RSD e da coleção de livros, do fortalecimento do boletim e do desenvolvimento de uma página eletrônica para interação com os associados e simpatizantes (CEBES, 2005D).

Paralelamente à análise crítica e posicionamento político da entidade diante dos fatos da conjuntura, a diretoria nacional desencadeou algumas ações direcionadas ao fortalecimento do Centro, como os projetos: Formação em Cidadania para a Saúde, o Memória e História do Cebes e Reforma Sanitária em Debate. O primeiro consistiu em cursos presenciais realizados pelos núcleos da entidade nos estados e de fóruns com especialistas, objetivando o debate de temas estratégicos para a RSB (CEBES, 2011B). O segundo, financiado pela Fiocruz, visava resgatar a história da entidade, tornando público seu acervo, contemplando a realização de uma série de entrevistas com ex-presidentes da entidade, como José Ruben de Alcântara Bonfim, Paulo Amarante, Volnei Garrafa, Sarah Escorel, José Gomes Temporão, entre outros, cujo conteúdo gravado foi disponibilizado no portal da entidade (CEBES, 2008A). Esse site, inclusive, foi dinamizado, sendo lançada sua nova versão em março de 2013 (http://cebes.org.br/). O projeto Reforma Sanitária em Debate, desenvolvido em parceria com a Organização Pan-Americana da Saúde (Opas), contemplou a realização de fóruns virtuais e presenciais, que abordaram os rumos da reforma sanitária naquele momento, gerando farto material que foi utilizado na editoração de revistas e da coleção de livros 'Pensar em saúde', assim nomeada em homenagem ao pensador latino-americano Mario Testa (FLEURY; LOBATO, 2009), cujo trabalho, ao longo dos últimos 50 anos, tem sido uma referência para os militantes da RSB.

Enquanto sujeito político coletivo que tem se colocado como defensor histórico do projeto e do processo da RSB, o Cebes abordou de forma recorrente nas publicações analisadas, de modo transversal, todas as temáticas desenvolvidas ao longo do período, sobretudo no que se refere a sua retomada e revitalização em cada contexto, denotando o seu compromisso já reconhecido na história da RSB (CEBES, 2005C; CEBES, 1979). Tal compromisso foi reafirmado durante o processo de 'refundação' do Cebes, a partir do qual a entidade voltou-se para a retomada do espírito crítico e do debate propositivo que deu origem ao projeto da RSB (CEBES, 2008B).

Esse processo contribuiu para a 'retomada do movimento sanitário', reconhecido pela própria entidade a partir de 2006. Essa retomada do projeto da RSB representa para o Cebes a tentativa de superar a

[...] dissociação entre Estado e sociedade, entre governo e forças sociais organizadas, entre as políticas e o sistema público e as necessidades e aspirações da população. (CEBES, 2006, P. 3).

Com esse objetivo, a entidade estimulou a análise sobre a configuração da RSB naquele momento e a reflexão se

[...] a institucionalidade que foi criada tem sido capaz de dar conta do projeto da Reforma Sanitária, adaptando-o às novas conjunturas e demandas que se apresentam na sociedade brasileira. (CEBES, 2006, P. 3).

Nesse movimento de atualização, o Cebes abordou, nos editoriais da RSD, uma diversidade de temáticas, como gênero, desenvolvimento sustentável, saúde para os grupos de lésbicas, gays, bissexuais, travestis e transgêneros e população negra, os quais refletiram as relações entre as novas demandas sociais e o aprofundamento da Reforma Sanitária, e até mesmo a reflexão e tomada de posicionamento político perante questões até então não abordadas pelo movimento sanitário, como a questão ambiental (CEBES, 2010D).

Essa atualização da agenda é uma ação destacada pelo Cebes ao defender que “[...] a 
Reforma Sanitária deve acompanhar o 'bonde da história', atualizar-se para corresponder à complexidade dos temas e demandas em saúde hoje", inclusive porque agrega novos atores (CEBES, 2007, P. 3) "[...] hoje fundamentais no movimento da saúde" (CEBES, 2007, P. 3).

Além da atualização de sua agenda, o Cebes reafirma continuamente seu antigo compromisso com o debate sobre a relação entre saúde e sociedade, ultrapassando a busca de solução dos problemas setoriais, destacando a diferença entre a importância/ profundidade do que se defendia nos anos 1980 ("levar a questão da democracia ao centro do debate e das decisões nacionais") e hoje (o movimento subdividiu-se em pautas talvez de menor envergadura) (CEBES, 2011A, P. 4).

A entidade reconhece, assim, a necessidade de renovação do movimento sanitário, por uma força jovem influenciada pelo uso das novas tecnologias da informação, mas destaca que se deu um "[...] afunilamento das energias políticas do movimento" (CEBES, 2011A, P. 4) em torno de dois tipos de problemas que são de natureza inteiramente setorial: a defesa do SUS e a defesa do modelo público da gerência dos hospitais do SUS. Tal subdivisão de pautas foi criticada porque descola a saúde do conjunto da sociedade e estreita o horizonte do debate desviando o foco das questões centrais (CEBES, 2011A, P. 4).

Nesse particular, o Cebes destaca duas temáticas centrais na agenda de debate: $o$ futuro da gestão do SUS e o futuro do modelo de desenvolvimento, defendendo que o que deve ser rechaçado em definitivo é a ideia de que tanto o SUS quanto o processo de desenvolvimento estejam voltados para consagrar somente os interesses do capital (CEBES, 2011A). Nesse sentido, chama a atenção para que, na última década, o movimento sanitário brasileiro tem "[...] retomado o papel de articulação dos movimentos em defesa do SUS e de crítica às políticas que impedem maiores avanços do sistema", como o baixo financiamento do setor, com destaque à luta pela ampliação do orçamento federal para a saúde (Saúde + 10) (CEBES, 2014C, P. 6). Reafirma, portanto, que o movimento sanitário tem se apresentado como porta-voz das demandas dos trabalhadores e usuários, apresentando propostas nas quais a saúde tenha papel central na melhoria das condições de vida de todos os brasileiros, recolocando-a, assim, na agenda nacional (CEBES, 2014A, P. 3).

Nessa discussão da relação entre sociedade e saúde tendo como perspectiva um novo processo de desenvolvimento centrado nos direitos e políticas sociais (CEBES, 2013), a entidade defende que "Os rumos e métodos do desenvolvimento não podem ser arbitrados nos gabinetes oficiais mediante um conluio com as grandes empresas" (CEBES, 2011A, P. 5) e, além disso, que é preciso garantir que

[...] os frutos do desenvolvimento possam ser revertidos para objetivos sociais de relevância nacional e que favoreçam a maturação progressiva de um Estado de Bem-Estar. (CEBES, 2011A, P. 5).

Diante desse desafio, o Cebes reconhece que seu sucesso só poderá ser alcançado mediante o fortalecimento do movimento sanitário pela sua “[...] aliança com os demais movimentos da sociedade civil" (CEBES, 2011A, P. 5), bem como por meio do fim dos subsídios ao setor privado e de sua efetiva regulação pelo Estado (CEBES, 2013). Nesse sentido, destaca a importância da análise da conjuntura política e econômico-social e a compreensão da globalização para a definição dos rumos do projeto da RSB (CEBES, 2011A). Esse processo de globalização é regido

[...] pelo capital e pelo mercado, [...] produzindo desigualdades e assimetrias [...] impondo um modelo de revolução tecnológica que acirra a condição de dependência e de atraso entre países, com repercussões para a saúde. (CEBES, 2012, P. 152-153).

Nesse particular, ampliando a ótica para o horizonte internacional, a entidade destaca 
a importância da articulação com os movimentos sociais dos demais países da América Latina, que constituem nichos de resistência aos ditames das agências internacionais, também fiéis à luta pelo direito à saúde e à construção de um mundo justo e igualitário (CEBES, 2009; 2014B; 2014C).

Retomar e atualizar a agenda política da RSB, conforme já foi dito, implica repensar seus objetivos e estratégias para construir novos arranjos sociais e políticos que garantam sua sustentação (CEBES, 2012). Nessa perspectiva, a entidade tem lutado continuamente pela revitalização do movimento sanitário e tem buscado construir uma reflexão crítica sobre as relações entre o Estado e a sociedade brasileira "[...] sob o prisma da economia política" (CEBES, 2012, P. 151), a fim de que surjam alternativas de transformação da economia e da política que contemplem mudanças nas atuais relações de poder da sociedade.

\section{Discussão e conclusões}

O processo de crise e refundação do Cebes marcou importante momento de inflexão na trajetória da entidade e implicou a reafirmação de sua identidade política e reorganização administrativa e financeira, os quais permitiram sua efetiva reativação, marcada nos anos seguintes pela sua atuação na arena política em saúde no Brasil, sempre pautada pela defesa da radicalização da democracia e dos princípios da RSB.

De fato, a refundação do Cebes desencadeou uma reflexão em torno das estratégias para a retomada e avanço do processo de RSB em uma conjuntura marcada pelo 'desencanto’ com o rumo das políticas econômicas e sociais adotadas pelos sucessivos governos federais eleitos democraticamente no período pós-1988. Vários autores apontam que tais governos implementaram políticas econômicas e sociais francamente marcadas pelo ideal neoliberal e, portanto, distantes da efetivação do SUS constitucional e do projeto da RSB (NORONHA; SOARES, 2001; COSTA, 2013; PAIM, 2013B).

Ultrapassada a crise, as diretorias nacionais que se sucederam no período estudado desenvolveram projetos direcionados à consolidação do Centro, os quais, de fato, marcaram a reativação dele, que retomou a publicação regular de sua revista e de outros documentos que contemplam a análise de temas relevantes no processo de luta política em saúde os quais subsidiaram a tomada de posição diante das medidas adotadas pelos governos no cenário político configurado ao longo do período estudado (TESTA, 2007). Nesse sentido, o Cebes, enquanto ator social, tem tido no setor saúde e no espaço social mais amplo um papel privilegiado na acumulação de poder técnico e político (TESTA, 1995) utilizado cotidianamente em função da difusão de conhecimentos científicos sobre a problemática de saúde e de valores democráticos que inspiram a defesa do direito à saúde enquanto direito de cidadania e o processo de construção do SUS.

O processo de refundação implicou, portanto, a retomada dos princípios e diretrizes que nortearam a criação da entidade nos anos 70 do século passado, que implicaram a atualização das suas estratégias diante do novo cenário político que se configurava na saúde e na sociedade brasileira. A ênfase concedida inicialmente à democratização da saúde e da sociedade permanece como eixo estruturante da atuação do Cebes, bem como a defesa do direito à saúde como direito de cidadania e do processo de implementação da RSB. Nessa perspectiva, a retomada da proposta original do Centro e do projeto histórico da RSB e sua atualização na conjuntura mais recente evidenciam a consciência histórica e política dos seus militantes e do seu corpo dirigente com relação ao que Paim (2008, P. 296) chamou de "promessas não cumpridas" da Reforma Sanitária, bem como da necessidade de reafirmar os princípios e diretrizes desse projeto. Em consonância com o referido autor, o Cebes defende que a RSB 
se desenvolveu com avanços e retrocessos, porém não se esgotou.

De fato, o debate mais recente acerca da vitalidade do processo de RSB aponta que não há consenso entre os estudiosos. Hochman (2013) argumenta que a RSB se findou como conjunto de ideias e práticas políticas, resultado de seu próprio êxito na proposição de uma agenda política e criação de um sistema de saúde reconhecido mundialmente, bem como da conquista da democracia em 1985. Contrariamente, Paim (2013B) defende que a RSB enquanto processo não terminou nem tem prazo de validade, o que pode ser evidenciado pela construção da Agenda Estratégica para a Saúde, pelas centenas de cidadãos formados pelo Cebes nos últimos anos e pela movimentação de milhares de participantes dos congressos da
Abrasco e das Conferências de Saúde.

Nesse sentido, contrariamente a alguns autores que têm considerado a RSB como ‘coisa do passado' identificando o SUS como sua realização maior, o Cebes soma-se àqueles que chamam atenção para que a implantação tortuosa do SUS não encerra em si o projeto mais amplo de reforma social proposto pelo movimento sanitário da década de 1970 (PAIM ET AL., 2011; PAIM, 2013B), cabendo novos esforços para a sua concretização. Em última instância, a entidade aposta na importância de ampliar a rearticulação dos movimentos sociais e identificação dos novos sujeitos políticos capazes de manter e ampliar a luta pela RSB, sobretudo na conjuntura política atual, marcada por ameaças cada vez maiores aos direitos constitucionais conquistados.

\section{Referências}

CENTRO BRASILEIRO DE ESTUDOS DE SAÚDE

(CEBES). Carta de Brasília [editorial]. Saúde debate,

Rio de Janeiro, v. 29, n. 70, p. 221-223, maio/ago. 2005 a.

. Carta do Brasil. 2014a. Disponível em: <http://

cebes.org.br/site/wp-content/uploads/2014/11/Carta. pdf $>$. Acesso em: 8 maio 2015.

A crise do Cebes [editorial]. Saúde debate, Rio de Janeiro, v. 29, n. 69, p. 3, jan./abr. 2005b.

Desenvolvimento e saúde [editorial]. Saúde

debate, Rio de Janeiro, v. 36, n. 93, p. 151-153, abr./jun, 2012.
Direito à Saúde: 25 anos [editorial]. Saúde

debate, Rio de Janeiro, v. 37, n. 96, p. 4-5, jan./mar. 2013.

Editorial. Saúde debate, Rio de Janeiro, v. 27, n.

64, p. 91-92, maio/ago., 2003.

Editorial. Saúde debate, Rio de Janeiro, v. 28, n.

67, p. 89, maio/ago., 2004.

Editorial. Saúde debate, Rio de Janeiro, v. 30, n.

72, p. 3-4, jan./abr. 2006.

Editorial. Saúde debate, Rio de Janeiro, v. 31, n.

75-77, p. 3, jan./dez. 2007. 
Editorial. Saúde debate, Rio de Janeiro, v. 32, n. 78-80, p. 3, jan./dez. 2008a.

O futuro do Cebes [editorial]. Saúde debate, Rio de Janeiro, v. 29, n. 70, p. 107, maio/ago., 2005c.

A identidade do Cebes. Saúde debate, Rio de Janeiro, v. 29, n. 71, p. 397-399, set./dez. 2005d.

Partidos, governo e os equívocos sobre o SUS [editorial]. Saúde debate, Rio de Janeiro, v. 33, n. 81, p. 3-5, jan./abr. 2009.

A questão democrática na área da saúde. Saúde debate, Rio de Janeiro, n. 9, p. 11-13, 1980.

Refundação do Cebes [editorial]. Saúde debate, Rio de Janeiro, v. 29, n. 71, p. 227-228, set./dez. 2005 e.

Linha do tempo: 2008. 2008b. Disponível em: <http://cebes.org.br/linha-do-tempo/ano-2008/>. Acesso em: 24 nov. 2016.

Editorial. Saúde debate, Rio de Janeiro, v. 35, n 88, p. 4-5, jan./mar, 2011a.

Editorial. Saúde debate, Rio de Janeiro, v. 35, n. 90, p. 346-348, jul./set. 2011 b.

Editorial. Saúde debate, Rio de Janeiro, v. 38, n. 103, p. 675-676, out./dez. 2014b.

Editorial. Saúde debate, Rio de Janeiro, v. 38, n. especial, p. 5-6, out. 2014c.

COSTA, A. M. Saúde e desenvolvimento. In: SADER, E. (Org.). 10 anos de governos pós-neoliberais no Brasil: Lula e Dilma. São Paulo: Biotempo; Rio de Janeiro: Flacso Brasil, 2013. p. 239-252.

ESCOREL, S. História das políticas de saúde no Brasil de 1964 a 1990: do golpe militar à reforma sanitária. In: GIOVANELLA, L. et al. (org.). Políticas e Sistemas de Saúde no Brasil. Rio de Janeiro: Fiocruz, 2008, p. 385-434.
Reviravolta na Saúde: origem e articulação do movimento sanitário. Rio de Janeiro: Fiocruz, 1999.

FLEURY, S. (Org.). Saúde e democracia: a luta do CEBES. São Paulo: Lemos Editorial, 1997.

Estado sem cidadãos: seguridade social na América Latina. Rio de Janeiro: Fiocruz, 1994.

FLEURY, S.; LOBATO, L. V. C. (Org.). Participação, Democracia e Saúde. Rio de Janeiro: Cebes, 2009.

HOCHMAN, G. Saudades do futuro ou um sistema de saúde em tempos democráticos. Cad. Saúde Pública, Rio de Janeiro, v. 29, n. 10, p. 1927-1953, out. 2013.

NORONHA, J. C.; SOARES, L. T. A política de saúde no Brasil nos anos 90. Ciência Saúde Coletiva, Rio de Janeiro, v. 6, n. 2, p. 445-450, 2001.

PAIM, J. S. A constituição cidadã e os 25 anos do Sistema Único de Saúde. Cad. Saúde Pública, Rio de Janeiro, v. 29, n. 10, p. 1927-1953, 2013 a.

Análise do processo da Reforma Sanitária Brasileira no período de 2007 a 2016. [s.d.]. Disponível em: <http://www.analisepoliticaemsaude.org/oaps/ eixos/apresentacao/?idx=9cfa9668242186748ea6acb23 f5c4c5c>. Acesso em: 25 nov. 2016.

. Reforma Sanitária Brasileira: eppur sinuove. Cad. Saúde Pública, Rio de Janeiro, v. 29, n. 10, p. 19271953, out, 2013.

Reforma Sanitária Brasileira: contribuição para a compreensão e crítica. Salvador: Edufba; Rio de Janeiro: Fiocruz, 2008

PAIM, J. S. et al. The Brazilian health system: history, advances, and challenges. The Lancet, London, 377, p. 1778-1797, 2011.

SANTOS, J. S.; TEIXEIRA, C. F. Política de saúde no Brasil: produção científica 1988-2014. Saúde debate, Rio de Janeiro, v. 40, n. 108, p. 219-230, jan./mar. 2016. 
SOPHIA, D. C. Saúde e Utopia: o Cebes e a Reforma Sanitária Brasileira. São Paulo: Hucitec; Sobravime, 2015 .

TEIXEIRA, S. F. (Org.). Reforma sanitária: em busca de uma teoria. São Paulo: Cortez; Abrasco, 1989.

TESTA, M. Decidir en Salud: ¿̨uén?, ¿Cómo? Y

¿Porqué? Salud Colectiva. Lanús, v. 3, n. 3, p. 247-257, set./dez., 2007.
Pensamento estratégico e lógica de programação: o caso da saúde. São Paulo: HUCITEC; Rio de Janeiro: Abrasco, 1995.

Recebido para publicação em agosto de 2016

Versão final em novembro de 2016

Conflito de interesses: inexistente

Suporte financeiro: não houve 